\title{
Induction of Heparin-binding Epidermal Growth Factor-like Growth Factor mRNA in Rat Kidney after Acute Injury
}

Toshio Homma, Masahiro Sakai, Hui Feng Cheng, Takashi Yasuda, Robert J. Coffey, Jr., and Raymond C. Harris Department of Medicine, Vanderbilt University School of Medicine, and the Department of Veterans Affairs Medical Center, Nashville, Tennessee 37232

\begin{abstract}
Previous studies have suggested that EGF or other members of the EGF family of mitogenic proteins are involved in proliferation of renal tubular epithelial cells occurring during recovery from injury to the kidney. The present studies examined whether expression of mRNA for the recently identified heparin-binding EGF-like growth factor (HBEGF) is regulated in response to renal injury induced by either ischemia/reperfusion or mercuric chloride. Increased expression of HB-EGF mRNA was demonstrated in the post-ischemic kidney within 45 min of unilateral ischemia/ reperfusion in the rat. Induction of HB-EGF mRNA occurred only when ischemia was followed by reperfusion, and was not eliminated by removal of blood cells from the post-ischemic kidney by saline perfusion. In situ hybridization with ${ }^{35} \mathrm{~S}$-labeled antisense riboprobes of HB-EGF indicated that compared with control, there was increased HBEGF mRNA expression in the $6 \mathrm{~h}$ post-ischemic kidney in the inner cortex and outer medulla in a patchy distribution, with the greatest expression in the inner stripe of the outer medulla. Expression occurred primarily in tubular epithelial cells. Recombinant human HB-EGF stimulated [ $\left.{ }^{3} \mathrm{H}\right]-$ thymidine incorporation in both primary cultures of rabbit proximal tubule cells and NRK 52E normal rat kidney epithelial cells, with potency similar to that of EGF. Induction of HB-EGF mRNA was observed in tubules freshly isolated from rat renal cortex or outer medulla when the tubules were subjected to reoxygenation after incubation in anoxic conditions. The nephrotoxin, mercuric chloride, also caused induction of HB-EGF mRNA both in vivo and in isolated rat cortical tubules. The anoxia/reoxygenation-induced expression of HB-EGF mRNA in isolated tubules was inhibited by the free radical scavengers, di- and tetra-methylthiourea, indicating involvement of reactive oxygen species. These findings indicate that HB-EGF mRNA is inducible in the kidney in vivo by acute tubular injury and suggest that HB-EGF may act as an autocrine/paracrine growth factor involved in proliferation of tubular epithelial cells and repair of the kidney. (J. Clin. Invest. 1995. 96:1018-1025.) Key words: kidney $\bullet$ acute tubular necrosis $\bullet$ ischemia/reperfusion injury • tubular epithelial cells
\end{abstract}

Preliminary accounts of this work have been published in abstract form (1993. J. Am. Soc. Nephrol. 4:747).

Address correspondence to Raymond C. Harris, M.D., Division of Nephrology, Department of Medicine, S-3223 Medical Center North, Vanderbilt University School of Medicine, Nashville, TN 37232. Phone: 615-343-0030; FAX: 615-343-7156.

Received for publication 13 October 1994 and accepted in revised form 3 May 1995.

The Journal of Clinical Investigation, Inc.

Volume 96, August 1995, 1018-1025

\section{Introduction}

The mammalian kidney is susceptible to injury by ischemia/ reperfusion and nephrotoxins, and subsequent restoration of renal architecture and function is characterized by proliferation of tubular epithelial cells and recovery of the damaged epithelial lining of the tubules (1). Accumulating evidence suggests that either EGF, or other members of the EGF family of mitogenic proteins, may play an important role in repair of the injured kidney (2).

In the rat, subcutaneous injection of EGF significantly accelerates both $\left[{ }^{3} \mathrm{H}\right]$ thymidine incorporation in tubular epithelial cells and recovery of tubular functions occurring in response to ischemia/reperfusion injury or nephrotoxic injury to the kidney (3-5). Continuous infusion of EGF by intra-aortic osmotic minipump has also been shown to augment recovery of tubular functions in the post-ischemic rat kidney (6). Ischemia/reperfusion injury to the kidney is followed by increases in ${ }^{125}$ I-EGF binding, with the greatest relative increases seen in the cortex and the proximal tubule (7). This increased EGF binding is detectable in the post-ischemic kidney by $24 \mathrm{~h}$ of reperfusion, whereas no changes are noted in the contralateral, non-ischemic kidney $(6,7)$. Similar increases in ${ }^{125}$ I-EGF binding have been observed in rat kidney subjected to folic acid-induced injury (8). EGF production in the mammalian kidney has been localized to the thick ascending limb of Henle and distal convoluted tubule (9). However, both ischemia/reperfusion injury and cisplatin renal toxicity lead to decreases in renal preproEGF mRNA levels and in urinary EGF excretion, with persistent inhibition for up to $7 \mathrm{~d}(10)$.

Several peptide growth factors have been shown to share structural homology with EGF and signal through EGF receptors. Mammalian members of this EGF family of mitogenic proteins include TGF- $\alpha$ (11), amphiregulin (12), and betacellulin (13). Heparin-binding EGF-like growth factor (HBEGF $)^{1}$, a $22-\mathrm{kD}$ protein that was originally purified from conditioned media of a macrophage-like cell line, U-937 cells (14, 15 ), is a recently discovered member of the EGF family. HBEGF has been shown to be a potent mitogen for vascular smooth muscle cells, keratinocytes and fibroblasts, but not for endothelial cells (14).

In the present studies, we examined whether expression of HB-EGF mRNA is associated with acute renal injury. The results show that both in vivo and in vitro, HB-EGF mRNA expression is induced in tubular epithelial cells in response to acute injury and suggest a role for HB-EGF as an autocrine and/or paracrine growth factor involved in renal regeneration.

1. Abbreviations used in this paper: FGF, fibroblast growth factor GAPDH, glyceraldehyde 3-phosphate dehydrogenase; HB-EGF, heparin-binding epidermal growth factor-like growth factor; HGF, hepatocyte growth factor; PMA, phorbol 12-myristate 13-acetate. 


\section{Methods}

Animal studies. Male Sprague-Dawley rats, weighing 150-200 grams, were used. Unilateral renal ischemia was induced by surgical clamping of the left renal artery for $50 \mathrm{~min}$ as previously described (16). In successful experiments, the kidney turned uniformly dark within 2-3 min, and normal color returned within 2-4 min after removal of the clamp, indicating reperfusion (16). At time intervals, rats were sacrificed and kidneys removed for total RNA extraction. Unless otherwise indicated, the nonclamped, contralateral kidney was used for the appropriate time control. Retrograde aortic perfusion with phosphate buffered saline was performed to remove blood from the kidney. In separate experiments, renal tubular injury was induced by a subcutaneous administration of mercuric chloride ( $5 \mathrm{mg} / \mathrm{kg}$ body wt) $5 \mathrm{~h}$ before time of killing (4).

Preparation of rat renal cortical and outer medullary tubule suspensions. Cortical tubule suspension was prepared from rat renal cortices by the methods of Vinay et al. (17), with slight modifications, as we have previously described (18). Tubules were suspended in Buffer A consisting of $115 \mathrm{mM} \mathrm{NaCl}, 24 \mathrm{mM} \mathrm{NaHCO}, 5 \mathrm{mM} \mathrm{KCl}, 1.5 \mathrm{mM}$ $\mathrm{CaCl}_{2}, 10 \mathrm{mM} \mathrm{MgSO}, 2.0 \mathrm{mM} \mathrm{NaH} \mathrm{PO}_{4}, 5 \mathrm{mM}$ glucose, $1 \mathrm{mM}$ alanine, $10 \mathrm{mM}$ Hepes, $\mathrm{pH}$ 7.4. Medullary tubules were prepared in Buffer A from outer medulla of rat kidneys as described by Chamberlin et al. (19), except that separation of the thick ascending limb by density gradient centrifugation was not performed.

Isolated rat tubules were subjected to anoxia and reoxygenation as described by $\mathrm{Yu}$ et al. (20). Isolated rat tubules were incubated for 30 min at $37^{\circ} \mathrm{C}$ in Buffer A pre-equilibrated in $95 \% \mathrm{~N}_{2} / 5 \% \mathrm{CO}_{2}$. Reoxygenation was induced by transferring the centrifuged tubules to Buffer A preequilibrated in $95 \% \mathrm{O}_{2} / 5 \% \mathrm{CO}_{2}$ and incubating at $37^{\circ} \mathrm{C}$ for an additional 30 or $60 \mathrm{~min}$, with continued superfusion with $95 \% \mathrm{O}_{2} / 5 \% \mathrm{CO}_{2}$.

Cell culture. Primary cultures of rabbit proximal tubule cells were prepared and grown in serum-free defined medium consisting of DME/ F12 medium supplemented with 100 units $/ \mathrm{ml}$ penicillin, $100 \mu \mathrm{g} / \mathrm{ml}$ streptomycin, $5 \mu \mathrm{g} / \mathrm{ml}$ insulin, $5 \mu \mathrm{g} / \mathrm{ml}$ transferrin, $10 \mathrm{nM}$ selenium, and $50 \mathrm{nM}$ hydrocortisone as we have previously described (21).

NRK 52E cells, an epithelial cell line derived from normal rat kidney (22), were cultured in DMEM supplemented with $10 \%$ fetal bovine serum, 100 units/ml penicillin, and $100 \mu \mathrm{g} / \mathrm{ml}$ streptomycin as previously described $(22,23)$.

Determination of $\left[{ }^{3} \mathrm{H}\right]$ thymidine incorporation. Cells were cultured in 24-well plates until confluency and incubated in DME/F12 medium free of defined additions (rabbit proximal tubule cells) or in serum-free DMEM medium (NRK 52E cells) for $48 \mathrm{~h}$ before addition of agonists. After $18 \mathrm{~h}$ of incubation with agonists, $1 \mu \mathrm{Ci} / \mathrm{ml}\left[{ }^{3} \mathrm{H}\right]$ thymidine was added and incubation was continued for an additional $2 \mathrm{~h}$. Cells were washed twice with ice-cold phosphate-buffered saline and incubated with $10 \%$ trichloroacetic acid for $30 \mathrm{~min}$ on ice. Acid-precipitable materials were dissolved in $0.25 \mathrm{M} \mathrm{NaOH} / 0.1 \%$ SDS and counted by scintillation spectrometry.

RNA isolation and Northern analysis. Total RNA was isolated by the acid guanidinium thiocyanate-phenol-chloroform method (24) and subjected to Northern blot analysis as we have previously described (25). Aliquots of total RNA, each consisting of $15 \mu \mathrm{g}$, were subjected to electrophoresis, transferred to S\&S Nytran nylon membranes (Schleicher \& Schuell, Keene, NH), and fixed to the membrane by exposing to UV. Following prehybridization, blots were hybridized with $2 \times 10^{6} \mathrm{cpm} / \mathrm{ml}$ of ${ }^{32} \mathrm{P}$-labeled cDNA overnight at $42^{\circ} \mathrm{C}$. A cDNA probe representing a 1.5-kb fragment of rat HB-EGF (26) was labeled to $>10^{8} \mathrm{cpm} / \mu \mathrm{g}$ by random priming procedure using a commercially available kit (Amersham, Arlington Heights, IL). The membranes were washed and exposed at $-70^{\circ} \mathrm{C}$ to Kodak X-Omat AR film with an intensifying screen. Blots were stripped and reprobed with a human GAPDH cDNA using the conditions of labeling, hybridization, and wash as described above. The levels of mRNA were quantitated by densitometry (Hoefer Scientific, San Francisco, CA) and normalized to GAPDH expression.

In situ hybridization. Procedures were essentially as described by Gaunt et al. (27). Kidneys were perfusion-fixed in situ with $1 \%$ para- formaldehyde in phosphate-buffered saline and immersed in 4\% paraformaldehyde. After graded alcohol dehydration, tissues were embedded in paraffin. Serial 7- $\mu \mathrm{m}$ sections were prepared on poly-L-lysine-coated slide glasses and were permeabilized in $0.2 \mathrm{M} \mathrm{HCl}$, followed by treatment with $1 \mu \mathrm{g} / \mathrm{ml}$ proteinase $\mathrm{K}$ at $37^{\circ} \mathrm{C}$ for $15 \mathrm{~min}$, refixed in $4 \%$ formaldehyde and treated with $0.1 \mathrm{M}$ triethanolamine in $0.25 \%$ (vol/ vol) acetic anhydride. A 1.5-kb fragment of rat HB-EGF ligated in pBSK (-) was linearized and ${ }^{35} \mathrm{~S}$-labeled, sense and anti-sense riboprobes were synthesized with $\mathrm{T} 3$ and $\mathrm{T} 7$ polymerase in the presence of ${ }^{35} \mathrm{~S}$ ] UTP and hydrolyzed to $\sim 300$ base fragments. After pre-hybridization, samples were hybridized at $45^{\circ} \mathrm{C}$ overnight in $50 \%$ formamide, 0.3 $\mathrm{M} \mathrm{NaCl}, 20 \mathrm{mM}$ Tris-HCl, pH 8.0, $5 \mathrm{mM}$ EDTA, $10 \mathrm{mM}$ DTT, $1 \times$ Denhardt's solution, $1 \mathrm{mg} / \mathrm{ml}$ yeast tRNA, and $10 \%$ dextran sulfate. Samples were successively washed in $2 \times$ SSC, washing buffer consisting of $50 \%$ formamide, $0.3 \mathrm{M} \mathrm{NaCl}, 20 \mathrm{mM}$ Tris- $\mathrm{HCl}, 1 \mathrm{mM}$ EDTA, $10 \mathrm{mM}$ DTT, and $0.2 \times$ Denhardt's solution, and finally in $0.1 \times \mathrm{SSC}$. The final wash also included post-hybridization treatment with RNase $A$ and RNase T1. The slide glasses were then dipped into emulsion of two-fold dilution of Kodak NTB2, exposed for 2 wk at $4^{\circ} \mathrm{C}$, developed with Kodak DEKTOL, and counterstained with hematoxylin and eosin.

Materials. $\left[\alpha-{ }^{32} \mathrm{P}\right] \mathrm{dCTP},\left[\alpha-{ }^{35} \mathrm{~S}\right] \mathrm{UTP}$ and $\left[{ }^{3} \mathrm{H}\right]$ thymidine were purchased from Du Pont-New England Nuclear (Boston, MA). EGF (receptor grade) was from Collaborative Research (Bedford, MA). Recombinant human HB-EGF was from R\&D Systems (Minneapolis, MN). The cDNAs for rat HB-EGF and human GAPDH, and NRK 52E cells were provided by Dr. Judith Abraham of Scios Nova, Inc., Dr. Naomasa Makita and Dr. Michael A. Haralson (Vanderbilt University), respectively. All other chemicals wwere from Sigma Chemical Co. (St. Louis, MO).

\section{Results}

Induction of HB-EGF mRNA in rat kidney by ischemia/reperfusion and mercuric chloride. We first examined expression of HB-EGF mRNA in kidneys subjected to ischemia/reperfusion injury. In the rat, unilateral renal ischemia was induced by clamping the renal artery for $50 \mathrm{~min}$. The clamp was then released and, at various times of reperfusion, kidneys were removed for extraction of total RNA, and levels of HB-EGF mRNA were examined by northern blot analysis (Fig. 1, left panels). In the post-ischemic kidney, a significant increase in HB-EGF mRNA levels was observed within $1 \mathrm{~h}$ of reperfusion. Expression of HB-EGF mRNA remained elevated at $6 \mathrm{~h}$ of reperfusion (8.0 \pm 2.0 -fold of that in the contralateral kidney; $n$ $=5 ; P<0.05)$ and in some experiments was still elevated at 24 and $48 \mathrm{~h}$.

Acute injury and subsequent regeneration of tubular epithelial cells are also induced by a variety of nephrotoxins, including mercuric chloride $(1,4)$. Mercuric chloride administration induced expression of HB-EGF mRNA in the kidney within $5 \mathrm{~h}$ (Fig. 1, right panels).

Expression of HB-EGF mRNA occurring in the post-ischemic kidney was localized by in situ hybridization using ${ }^{35} \mathrm{~S}$ labeled antisense riboprobes prepared from rat HB-EGF cDNA (Fig. 2). A low power dark-field photomicrograph of the 6 h post-ischemic kidney (Fig. $2 \mathrm{~A}$ ) indicated the presence of hybridization with an anti-sense cRNA probe to rat HB-EGF in the medulla and cortex in a patchy distribution, with the most intense hybridization signals in the inner stripe of the outer medulla and patchier signals in the outer medulla and cortex. There was no detectable hybridization in the inner medulla (Fig. $2, A-2)$. In the contralateral non-ischemic kidney, anti-sense probes did not detect significant hybridization in the inner stripe of the outer medulla (Fig. $2 B$ ). The specificity of the hybridization signals was confirmed by the lack of any hybridization in 
Ischemia / Reperfusion
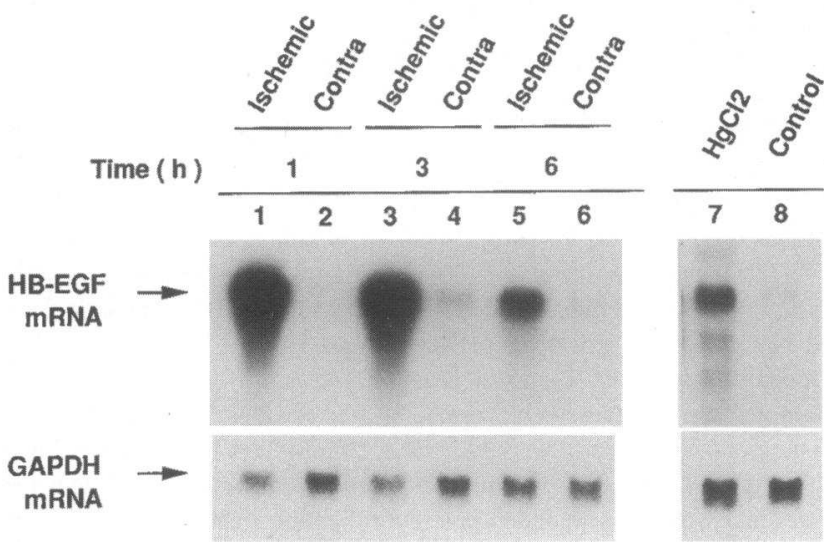

Figure 1. Induction of HB-EGF mRNA in rat kidney in vivo after acute injury by ischemia/reperfusion or mercuric chloride. (Left panels) Rats were subjected to unilateral renal ischemia/reperfusion injury and, at the indicated times of reperfusion, both ischemic (Ischemic) and nonischemic, contralateral (Contra) kidneys were removed and total RNA was extracted as described in Methods. Aliquots of total RNA ( $15 \mu \mathrm{g}$ ) were subjected to Northern analysis for HB-EGF mRNA expression as described in Methods. (Right panels) In separate experiments, mercuric chloride was administered to rats. At $5 \mathrm{~h}$, kidneys were removed, and total RNA was extracted and subjected to Northern analysis for HBEGF mRNA expression as described in Methods. A representative autoradiograph of eight separate experiments is shown. Expression of GAPDH mRNA is also presented.

the post-ischemic kidney using sense probes (Fig. $2 C$ ). Higher power photomicrographs of the inner stripe of the outer medulla (Fig. 2, $D$ and $E$ ) showed that expression of HB-EGF mRNA in the post-ischemic kidney was detected primarily in tubular epithelial cells, predominantly collecting tubules, with occasional expression in thick ascending limbs. In the outer stripe of the outer medulla (Fig. 2, $F$ and $G$ ), intense hybridization was also detected in collecting tubules (Fig. $2 F$, arrow). In addition, there was patchy hybridization noted in medullary thick ascending limbs (Fig. 2 G, arrow), with minimal hybridization in proximal straight tubules (Fig. $2 G$, arrowhead).

Since necrosis and subsequent regeneration of tubular epithelial cells in the post-ischemic kidney is most prominent in proximal tubules, the localization of HB-EGF mRNA expression to distal tubular structure suggested that endogenous HBEGF might serve as a paracrine growth factor involved in proliferation of proximal tubule cells. To determine whether proximal tubules respond to HB-EGF, we examined mitogenic activity of recombinant human HB-EGF in primary cultures of rabbit proximal tubule cells (Fig. $3 A$ ). Incubation of cells with either EGF or recombinant HB-EGF stimulated incorporation of $\left[{ }^{3} \mathrm{H}\right]-$ thymidine in a concentration-dependent manner (Fig. $3 A$ ). In rabbit proximal tubule cells, maximal 3.8- and 4.0-fold stimulation was observed at 3.3 and $1.7 \mathrm{nM}$ of EGF and recombinant HB-EGF, respectively. EC50 was seen at $0.3 \mathrm{nM}$ and $0.6 \mathrm{nM}$ for EGF and recombinant HB-EGF, respectively (Fig. $3 A$ ). We performed similar studies in a rat renal epithelial cell line, NRK 52E (Fig. $3 \mathrm{~B}$ ). In these cells, EGF and recombinant HBEGF caused maximal 5.0- and 5.5-fold stimulation of $\left[{ }^{3} \mathrm{H}\right]-$ thymidine incorporation at 3.3 and $1.7 \mathrm{nM}$, respectively. EC50 was observed at $0.3 \mathrm{nM}$ and $0.8 \mathrm{nM}$ for EGF and recombinant HB-EGF, respectively.

Previous studies have suggested an important role for reper- fusion in initiation of the full range of responses following ischemic injury (1). Therefore, we examined whether induction of HB-EGF mRNA in the post-ischemic kidney was dependent on subsequent reperfusion. In the experiments shown in Fig. 4 $A$, kidneys were subjected to either 45 or $90 \mathrm{~min}$ of ischemia without reperfusion, or to $45 \mathrm{~min}$ of ischemia with subsequent reperfusion for $45 \mathrm{~min}$. Ischemia alone did not affect HB-EGF mRNA levels. In contrast, when the kidneys were reperfused, the level of HB-EGF mRNA was significantly increased (Fig. $4 A$ ). These findings indicated that ischemia and subsequent reperfusion, rather than ischemia alone, was required for full induction of HB-EGF mRNA in vivo.

We also examined whether stasis of hematopoietic cells in the post-ischemic kidney was contributing to the increased HBEGF mRNA levels (Fig. $4 \mathrm{~B}$ ). Three hours after the release of the renal artery clamp, both contralateral and post-ischemic kidneys were flushed in situ with phosphate buffered saline prior to extraction of total RNA (Fig. $4 B$ ). Saline perfusion did not alter the increased HB-EGF mRNA expression seen in the post-ischemic kidney. These observations confirmed the in situ findings that the observed induction of HB-EGF mRNA occurred in either intrinsic renal cells or infiltrating inflammatory cells.

Induction of HB-EGF $m R N A$ in rat renal cortical and outer medullary tubule suspension in vitro. The in vivo studies demonstrated that renal injury by ischemia/reperfusion resulted in increased HB-EGF mRNA expression in the damaged kidney in both cortex and outer medulla. To examine further the inducibility of HB-EGF mRNA in tubules under the conditions similar to that of the in vivo studies, but in the absence of either infiltrating inflammatory cells or intrinsic nontubular renal cells, we used tubules freshly isolated from either renal cortex or outer medulla of the rat. Cortical tubules were isolated from control rat kidneys and incubated for 30 min under anoxic conditions, with or without subsequent reoxygenation for an additional $60 \mathrm{~min}$ (Fig. $5 \mathrm{~A}$ ). Whereas the level of HB-EGF mRNA was significantly increased in the tubules subjected to anoxic conditions, full induction was observed following reoxygenation. Incubation of the tubules for $90 \mathrm{~min}$ with mercuric chloride also resulted in induction of HB-EGF mRNA (Fig. $5 A$ ). Low levels of HB-EGF mRNA were also observed in freshly isolated medullary tubules (Fig. $5 \mathrm{~B}$ ). Similar to the findings in cortical tubules, HB-EGF mRNA expression in the outer medullary tubule suspensions was increased following incubation under anoxic conditions and markedly augmented upon reoxygenation (Fig. $5 B$ ).

Since reactive oxygen species have been suggested to mediate functional and structural alterations that occur in response to ischemic injury $(1,28)$, we examined effects of free radical scavengers, di- and tetra-methylthiourea (29) on expression of HB-EGF mRNA induced by anoxia/reoxygenation in isolated rat renal tubules (Fig. 6). The level of HB-EGF mRNA in freshly isolated cortical tubules remained very low upon $90 \mathrm{~min}$ of incubation under control conditions. Incubation under anoxic condition for $30 \mathrm{~min}$ increased expression of HB-EGF mRNA and subsequent reoxygenation resulted in a further increase in HB-EGF mRNA expression. When reoxygenation was performed in the presence of either dimethylthiourea or tetramethylthiourea, induction of HB-EGF mRNA was significantly inhibited (Fig. $6 A$ ). In similar experiments performed on freshly isolated rat outer medullary tubules, the anoxia/reoxygenationinduced increases in HB-EGF mRNA expression were reduced in the presence of these free radical scavengers (Fig. $6 \mathrm{~B}$ ). In 

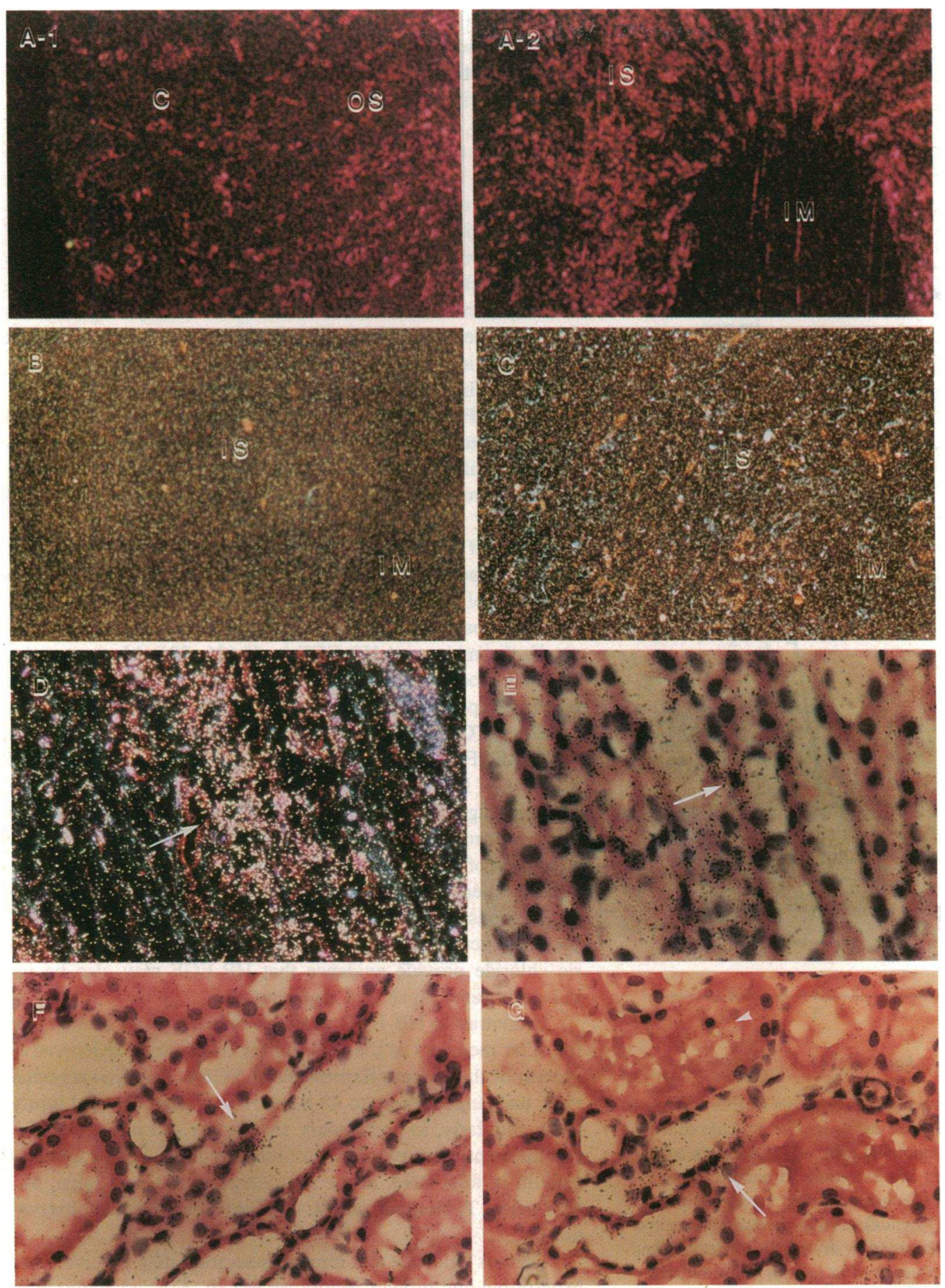

Figure 2. In situ hybridization for expression of HB-EGF mRNA in rat kidney following ischemia/reperfusion. Rats were subjected to 50 min of unilateral ischemia and, after $6 \mathrm{~h}$ of reperfusion, kidneys were fixed in situ and analyzed for expression of HB-EGF mRNA by in situ hybridization as described in Methods. $C$, cortex; $O S$, outer stripe of the outer medulla; $I S$, inner stripe of the outer medulla; $I M$, inner medulla. $(A)$ Dark-field photomicrograph of the post-ischemic kidney hybridized with an anti-sense probe $(\times 50)$. Expression of HB-EGF mRNA, appearing as bright pink signals, occurred in a patchy distribution. Expression was most intense in IS (A-2) and patchier in OS and C (A-1). No hybridization occurred in IM $(A-2) .(B)$ Dark-field photomicrograph of IS of the contralateral non-ischemic kidney hybridized with an anti-sense probe $(\times 100) .(C)$ Darkfield photomicrograph of IS of the post-ischemic kidney hybridized with a sense probe $(\times 100)$. $(D)$ Dark-field photomicrograph at a higher magnification $(\times 400)$ of IS of the post-ischemic kidney hybridized with an anti-sense probe, showing intense hybridization in collecting tubules (arrow). (E) Bright-field photomicrograph of IS of the post-ischemic kidney similar to that of D at a higher magnification $(\times 800)$. The black grains indicate positive hybridization for HB-EGF mRNA. $(F)$ Bright-field photomicrograph of OS of the post-ischemic kidney hybridized with an anti-sense probe $(\times 400)$. HB-EGF mRNA was expressed in collecting tubules (arrow). (G) Bright-field photomicrograph of OS of the postischemic kidney hybridized with an anti-sense probe $(\times 600)$. HB-EGF mRNA was expressed in thick ascending limbs (arrow), with minimal expression in proximal straight tubules (arrowhead). 

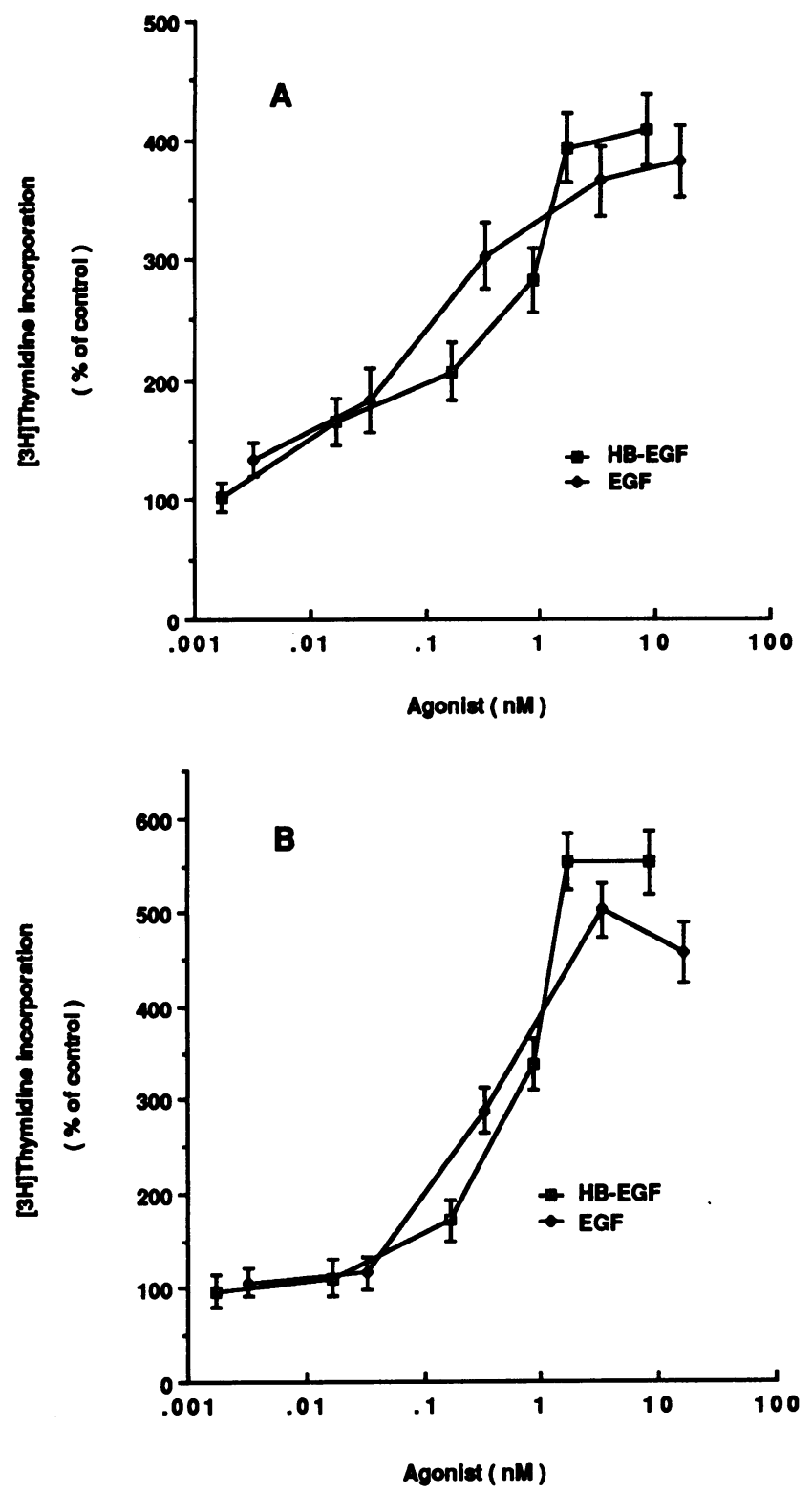

Figure 3. Stimulation of $\left[{ }^{3} \mathrm{H}\right]$ thymidine incorporation by EGF or recombinant HB-EGF in primary cultures of rabbit proximal tubule cells $(A)$ or NRK 52E normal rat kidney epithelial cells $(B)$. Quiescent cells were incubated with the indicated concentrations of either EGF or recombinant HB-EGF for $18 \mathrm{~h}$, and further incubated for an additional 2 $\mathrm{h}$ in the presence of $1 \mu \mathrm{Ci} / \mathrm{ml}\left[{ }^{3} \mathrm{H}\right]$ thymidine. Acid-precipitable incorporation of $\left[{ }^{3} \mathrm{H}\right]$ thymidine was determined as described in Methods and expressed as percentage of the values seen in control nonstimulated cells.

these experiments on isolated tubules, we occasionally observed the appearance of a second mRNA species with an approximate size of $1.6 \mathrm{~kb}$. The identity of this mRNA species is currently under investigation. In other experiments, anoxia/reoxygenation-induced expression of HB-EGF mRNA in isolated rat cortical tubules was also significantly inhibited by superoxide dismutase, with a lesser degree of inhibition observed with catalase.

\section{Discussion}

Recovery of kidney integrity after acute renal injury is characterized by structural as well as functional repair of the damaged epithelium $(1,2)$. Since alterations in EGF binding occur in injured kidneys (6-8) and EGF administration augments recovery of function (3-5), it has been suggested that EGF may participate in regenerative growth of the kidney. However, against this hypothesis is the observation that expression of preproEGF mRNA is significantly decreased following acute renal injury by ischemia/reperfusion (7) or cis-platin-induced nephrotoxicity (10). This decrease in renal EGF production led us to examine whether other mitogenic proteins of the EGF family might be involved in regeneration of the kidney. In the present studies, we have provided evidence that HB-EGF, a recently identified member of the EGF family, represents a potential mediator of renal regeneration by demonstrating that acute renal injury by ischemia/reperfusion or mercuric chloride resulted in induction of mRNA for HB-EGF.

HB-EGF was originally identified as a heparin-binding mitogen secreted by cultured human macrophages and was subsequently purified as a $21-\mathrm{kD}$ peptide by heparin-affinity chromatography from conditioned media of a macrophage-like cell line, U-937 cells $(14,15)$. In addition to macrophages (14), induction of HB-EGF mRNA occurred in vascular endothelial cells in response to TNF- $\alpha$, bacterial endotoxin, and lysophosphatidylcholine $(30,31)$ and in vascular smooth muscles cells by PDGF, basic fibroblast growth factor (basic FGF), angiotensin II, thrombin, and HB-EGF itself $(26,32)$. More recently, it was demonstrated that HB-EGF mRNA was inducible in rat intestinal epithelial cell line by members of the EGF family, including TGF- $\alpha$, amphiregulin, and HB-EGF (33).

HB-EGF is mitogenic for vascular smooth muscle cells, and fibroblasts (14), as well as intestinal epithelial cells (33). These findings suggest a role for HB-EGF as an autocrine and/or paracrine growth factor in wound repair and tissue regeneration. In support of this hypothesis, induction of HB-EGF was recently demonstrated in wound fluid of skin (34). The present in vivo observations that HB-EGF mRNA expression occurs in response to acute renal injury by ischemia/reperfusion or mercuric chloride provide evidence that HB-EGF may also be involved in renal repair and regeneration.

In contrast to HB-EGF, available data suggest a limited role for other members of the EGF family in initiating regenerative growth of the kidney. Expression of TGF- $\alpha$ has been reported to be unchanged for up to $48 \mathrm{~h}$ following ischemic renal injury (35). Similarly, in preliminary studies, we did not detect discernible expression of mRNA for amphiregulin, TGF- $\alpha$, or betacellulin in total RNA in the post-ischemic kidney (Sakai, M., T. Yasuda, T. Homma, and R. C. Harris, unpublished observations).

There is evidence that renal regeneration may involve other heparin-binding growth factors, $\operatorname{HGF}(36,37)$ and acidic FGF (38). The present results indicate that in ischemic renal injury, increased expression of HB-EGF mRNA occurs earlier than HGF or acidic FGF. Whereas HB-EGF mRNA expression is elevated within $1 \mathrm{~h}$ after ischemia, significant induction of HGF mRNA is noted $6 \mathrm{~h}$ after ischemic renal injury (36), and acidic FGF mRNA expression is not demonstrable until $5 \mathrm{~d}$ after nephrotoxic injury (38).

In recently reported preliminary studies (39), control or 6 $h$ post-ischemic rat kidneys were homogenized, solubilized, and subjected to batch elution from a heparin sepharose column followed by fractionation with a TSK heparin affinity column using methods previously described by Higashiyama et al. (14). The results indicated that in the $6 \mathrm{~h}$ post-ischemic kidney, there was a marked increase in heparin binding proteins that exhibit 
A
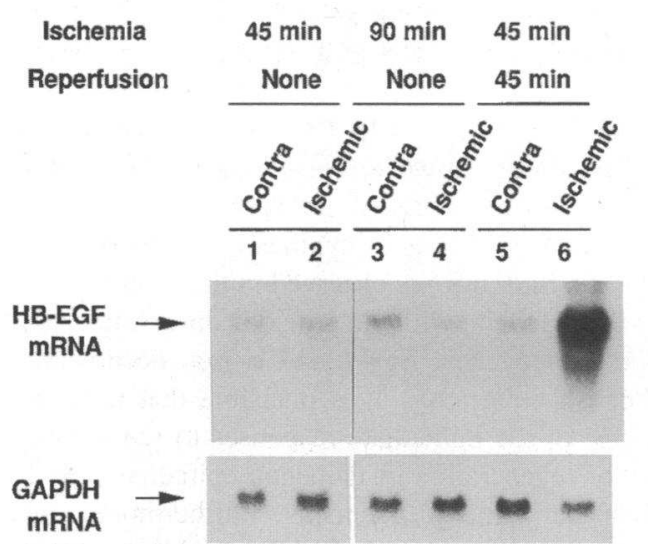

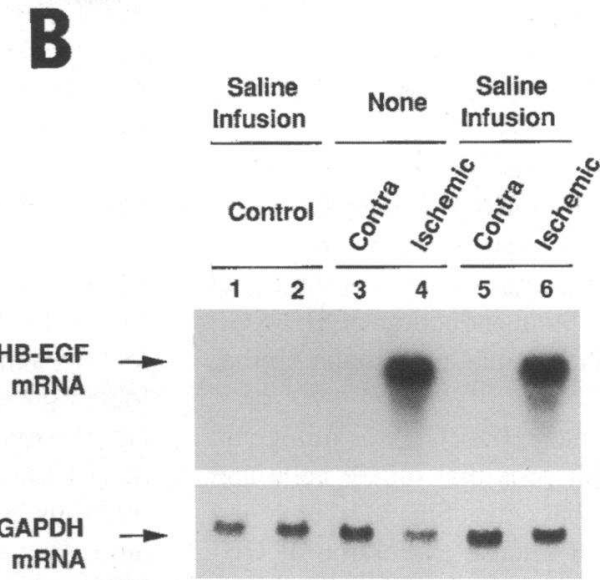

Figure 4. Roles for reperfusion and stasis of hematopoietic cells in ischemia/reperfusion-induced expression of HB-EGF mRNA in rat kidney. (A) Dependence on reperfusion of ischemia/reperfusion-induced expression of HB-EGF mRNA in rat kidney. Rats were subjected to either 45 or 90 min of unilateral renal ischemia alone, or to $45 \mathrm{~min}$ of unilateral renal ischemia with subsequent $45 \mathrm{~min}$ of reperfusion. Expression of HB-EGF mRNA expression was determined in both ischemic (Ischemic) and non-ischemic, contralateral (Contra) kidneys by Northern analysis as described in Methods. $(B)$ Lack of effect of blood removal from post-ischemic kidney on ischemia/reperfusion-induced expression of HB-EGF mRNA. Rats were subjected to unilateral ischemia/reperfusion. At $3 \mathrm{~h}$ of reperfusion, blood was removed from both post-ischemic (Ischemic) and contralateral, non-ischemic (Contra) kidney by retrograde aortic flushing with phosphate buffered saline before extraction of total RNA. Expression of HB-EGF mRNA expression was determined by Northern analysis as described in Methods.

an elution profile characteristic of HB-EGF, mitogenic activity for Balb/c 3T3 cells, NRK 52E cells or an EGF-sensitive rat intestinal epithelial cell line, and activation of EGF receptor tyrosine kinase activity in A431 cell membranes (39).

A
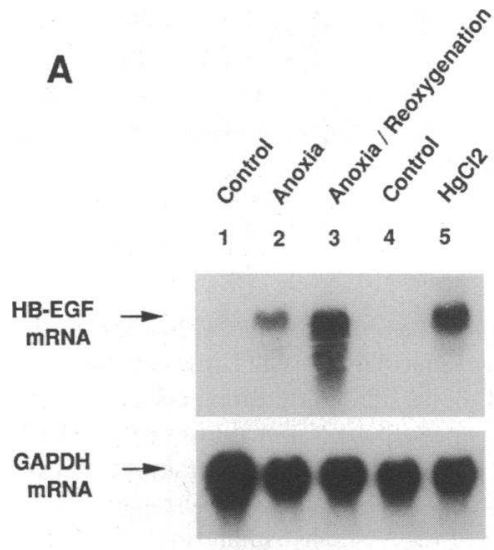

B
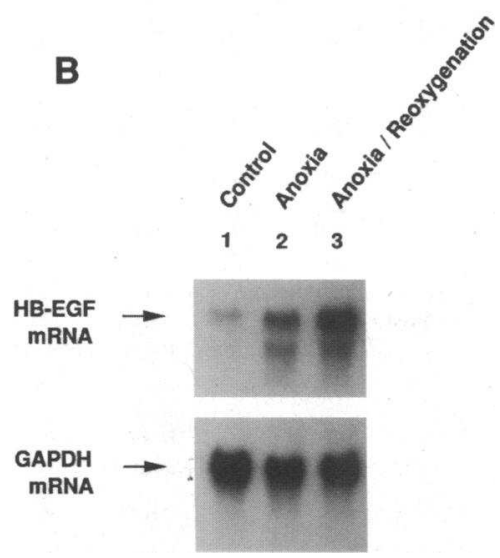

Figure 5. HB-EGF mRNA expression in freshly isolated rat renal tubules by exposure to anoxia, reoxygenation, and mercuric chloride. Cortical $(A)$ or outer medullary $(B)$ tubules were isolated from rat kidneys and incubated under control conditions for $90 \mathrm{~min}$ (Control), $\min$ (Anoxia), anoxic conditions for $30 \mathrm{~min}$ followed by reoxygenation for $60 \mathrm{~min}$ (Anoxial Reoxygenation), or with $5 \mu \mathrm{g} / \mathrm{ml}$ mercuric chloride for $90 \min \left(\mathrm{HgCl}_{2}\right)$ as described in Methods. Total RNA was extracted and subjected to Northern analysis as described in Methods. anoxic conditions for 30

In situ hybridization revealed that in the post-ischemic kidney, HB-EGF mRNA expression was localized to the inner cortex and outer medulla in a patchy distribution. At the time point examined ( $6 \mathrm{~h}$ post-ischemia), HB-EGF mRNA expression was observed primarily in the medullary thick ascending limbs and cortical and medullary collecting ducts. Since tubular epithelial cells of the outer medulla are most susceptible to

A

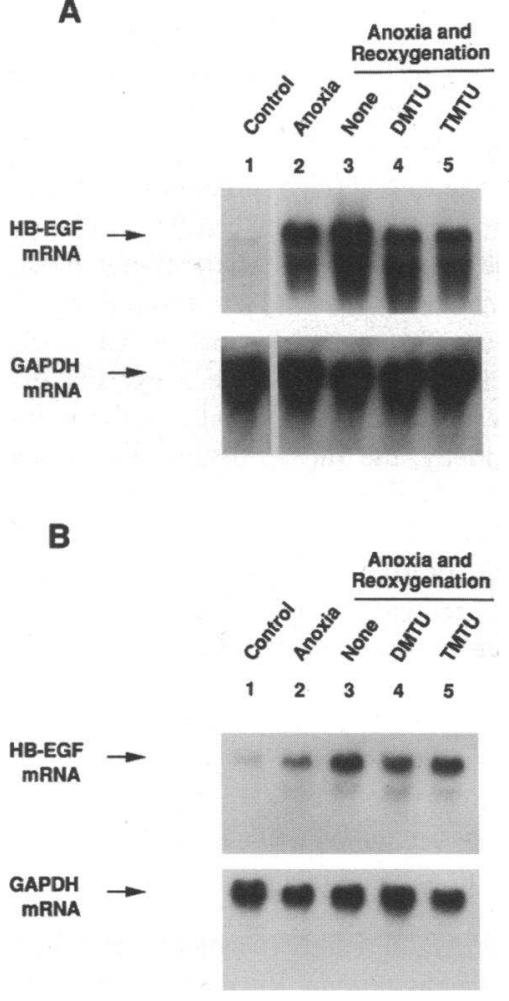

Figure 6. Effects of oxygen radical scavengers on HB-EGF mRNA expression induced by anoxia/reoxygenation in freshly isolated rat renal tubules. Freshly isolated rat cortical $(A)$ or outer medullary $(B)$ tubules were incubated under control conditions for 90 $\min ($ Control), anoxic conditions for $30 \mathrm{~min}$ (Anoxia), or anoxic conditions for $30 \mathrm{~min}$ followed by reoxygenation for $60 \mathrm{~min}$ (Anoxia and Reoxygenation $)$ in the absence (None) or presence of $10 \mathrm{mM}$ dimethylthiourea $(D M T U)$ or tetramethylthiourea (TMTU). Total RNA was extracted and subjected to Northern analysis as described in Methods. 
ischemic injury, the observed intense HB-EGF mRNA expression in tubular epithelial cells in this region suggests that mediators of ischemic injury and subsequent regeneration of tubular epithelial cells are closely linked with induction of HB-EGF mRNA. The distribution of HB-EGF mRNA expression in the post-ischemic kidney is in contrast to that of hepatocyte growth factor (HGF). Expression of HGF mRNA occurring in the post-ischemic kidney is localized to interstitial cells, including endothelial cells and macrophages, but not in tubular epithelial cells (36). These findings suggest that induction of HB-EGF may be more closely associated with damage to tubular epithelium than that of HGF.

We demonstrated that recombinant HB-EGF was mitogenic for both primary cultures of rabbit proximal tubule cells and NRK 52E normal rat kidney epithelial cells (Fig. 3). Combined with the observations that the most intense expression of HBEGF mRNA was localized to tubular epithelial cells in the outer medulla, the observed mitogenic activity of HB-EGF for cultured proximal tubule cells indicates that endogenous HBEGF may serve as a paracrine growth factor for the proximal tubule. While the nephron segment origin of NRK 52E normal rat kidney epithelial cells has not been fully characterized, these cells have recently been shown to express functionally active mineralcorticoid receptors characteristic of distal tubules (40, 41 ). Thus, the present results suggest that HB-EGF may also be involved in repair or regeneration of distal tubules in an autocrine fashion. In this regard, recent reports have indicated that apoptosis of distal tubular epithelial cells occurred after ischemia (42) or aminoglycoside injury (43), two renal insults known to induce proximal tubule necrotic injury. Since EGF administration has been shown to decrease apoptosis in both mesenchimally derived and ureteric-bud derived cells during development (44), it can be speculated that local production of HB-EGF in distal nephron may serve an autocrine and/or paracrine function to limit apoptosis in these segments.

We found that reperfusion of the ischemic kidney was necessary for full induction of HB-EGF mRNA in vivo (Fig. $4 A$ ). Similarly, reoxygenation of isolated rat renal cortical or outer medullary tubules was required for full induction of HB-EGF mRNA after incubation under anoxic conditions (Fig. 5). In these experiments, it is possible that the increased expression of HB-EGF mRNA seen after anoxia/reoxygenation may have been a reflection of the time required for the cellular machinery to achieve induction of the HB-EGF gene. Alternatively, induction of HB-EGF mRNA may have occurred as a result of reactivation of metabolic pathways that are only operative when cells are oxygenated. However, other studies have suggested that whereas ischemia per se causes certain functional and morphologic alterations in the kidney, the full spectrum of ischemic renal injury occurs upon reperfusion, as a result of free radical production (1). In vivo studies have shown that loss of renal function seen after ischemic or glycerol-induced injury is ameliorated by either hydroxyl radical scavengers or inhibition of hydroxy radical production by iron chelators $(28,45)$.

In the present studies, the free radical scavengers, dimethylthiourea and tetramethylurea reduced induction of HB-EGF mRNA occurring in response to anoxia/reoxygenation in freshly isolated rat cortical and outer medullary tubules (Fig. 6). The anoxia/reoxygenation-induced expression of HB-EGF mRNA was more sensitive to oxygen radical scavengers in isolated cortical tubules than in outer medullary tubules (Fig. 6 ), suggesting that involvement of reactive oxygen species may vary between these tubule preparations. Recently, it has been proposed that oxygen radicals may function as second messengers for gene activation, in particular for genes under the regulation of the transcription factor NF- $\kappa B(46-48)$. It is possible that the observed induction of HB-EGF mRNA occurs through similar pathways.

In vascular smooth muscle cells (32) and mesangial cells (49), HB-EGF has been shown to behave as an "immediate early gene," with agonist-induced increases in mRNA occurring in the presence of protein synthesis inhibitors. Thus, the induction of HB-EGF mRNA observed in the post-ischemic kidney is in close agreement with the previous observations that induction of protooncogenes, $E g f-1$ and c-fos, occurs upon reperfusion after ischemia (50). It is plausible that induction of HB-EGF is one of the immediate responses to renal injury, initiating repair or regeneration of damaged epithelial cells by autocrine and/or paracrine mechanisms. Furthermore, since EGF receptor expression is known to be increased by activation of the EGF receptor $(51,52)$, increased HB-EGF expression in the post-ischemic kidney may mediate the increase in EGF receptor density seen within $24 \mathrm{~h}$ of ischemic insult (7).

In summary, we have demonstrated that renal injury by either ischemia/reperfusion or mercuric chloride resulted in induction of HB-EGF mRNA both in vivo and in vitro. Induction of HB-EGF mRNA in the post-ischemic kidney was localized primarily to tubular epithelial cells in the inner cortex and outer medulla. We also demonstrated that recombinant HB-EGF was mitogenic for primary cultures of rabbit proximal tubule cells and NRK 52E normal rat kidney epithelial cells. By using tubules freshly isolated from either rat renal cortex or outer medulla, we showed that HB-EGF mRNA was inducible in renal tubular epithelial cells. Finally, we provided evidence that reactive oxygen species were involved in induction of HB-EGF mRNA that occurred in isolated renal tubules in response to anoxia/reoxygenation. In addition to the recent demonstration of HB-EGF proteins in wound fluid of skin (31), the present findings represent a pathophysiological setting in which HBEGF may play a significant role in the regenerative growth of the organ.

\section{Acknowledgments}

We are grateful to Dr. Judith Abraham of Scios Nova, Inc. for rat HBEGF cDNA, and Dr. Shigeru Kiyama of Vanderbilt University for expert assistance in interpretation of the in situ hybridization studies.

This work was supported in part by the National Institutes of Health grants DK-39261, DK-38226, and CA-46413, and Veterans Administration Funds. Drs. Harris and Coffey are Clinical Investigators in the Career Development Program of the Veterans Administration.

\section{References}

1. Bonventre, J. V. 1993. Mechanisms of ischemic acute renal failure. Kidney Int. 43:1160-1178.

2. Toback, F. G. 1992. Regeneration after acute tubular necrosis. Kidney Int. 41:226-246.

3. Humes, H. D., D. A. Cieslinski, T. M. Coimbra, J. M. Messana, and C. Calvao. 1989. Epidermal growth factor enhances renal tubule cell regeneration and repair and accelerates the recovery of renal function in postischemic acute renal failure. J. Clin. Invest. 84:1757-1761.

4. Coimbra, T. M., D. A. Cieslinski, and H. D. Humes. 1990. Epidermal growth factor accelerates renal repair in mercuric chloride nephrotoxicity. Am. J. Physiol. 259:F438-F443.

5. Morin, N. J., G. Laurent, D. Nonclercq, G. Toubeau, J-A. Heuson-Stiennon, M. G. Bergeron, and D. Beauchamp. 1992. Epidermal growth factor accelerates renal tissue repair in a model of gentamicin nephrotoxicity in rats. Am. J. Physiol. 263:F806-F811.

6. Norman, J. T., Y. K. Tsau, A. Bacay, and L. G. Fine. 1990. Epidermal 
growth factor accelerates functional recovery from ischaemic acute tubular necrosis in the rat: role of the epidermal growth factor receptor. Clin. Sci. 78:445450.

7. Safirstein, R., P. M. Price, S. J. Saggi, and R. C. Harris. 1990. Changes in gene expression after temporary renal ischemia. Kidney Int. 37:1515-1521.

8. Behrens, M. T., A. L. Corbin, and M. K. Hise. 1989. Epidermal growth factor receptor regulation in the rat kidney: two models of renal growth. Am. J. Physiol. 257:F1059-1066.

9. Rall, L. B., J. Scott, G. I. Bell, R. J. Crawford, J. D. Penshcow, H. D. Niall, and J. P. Coghlan. 1985. Mouse prepro-epidermal growth factor synthesis by the kidney and other tissues. Nature (Lond.). 313:228-232.

10. Safirstein, R., A. Zelent, and P. M. Price. 1989. Reduced preproEGF mRNA and diminished EGF excretion during acute renal failure. Kidney Int. 36:810-815.

11. Massague, J. 1990. Transforming growth factor- $\alpha$. J. Biol. Chem. 265:21393-21396.

12. Shoyab, M., V. L. McDonald, J. G. Bradley, and G. J. Todaro. 1988 Amphiregulin: a bifunctional growth-modulating glycoprotein produced by the phorbol 12-myristate 13-acetate-treated human breast adenocarcinoma cell line MCF-7. Proc. Natl. Acad. Sci. USA. 85:6528-6532.

13. Shing, Y., G. Christofori, D. Hanahan, Y. Ono, R. Sasada, K. Igarashi, and J. Folkman. 1993. Betacellulin: A mitogen from pancreatic $\beta$ cell tumors Science (Wash. DC). 259:1604-1607.

14. Higashiyama, S., J. A. Abraham, J. Miller, J. C. Fiddes, and M. Klagsbrun. 1991. A heparin-binding growth factor secreted by macrophage-like cells that is related to EGF. Science (Wash. DC). 251:936-939.

15. Higashiyama, S., K. Lau, G. E. Besner, J. A. Abraham, and M. Klagsbrun 1992. Structure of heparin-binding EGF-like growth factor. J. Biol. Chem. 267:6205-6212.

16. McKanna, J. A., A. Chuncharunee, K. A. Munger, J. A. Breyer, S. Cohen, and R. C. Harris. 1992. Localization of p35 (Annexin I, Lipocortin I) in norma adult rat kidney and during recovery from ischemia. J. Cell. Physiol. 153:467476.

17. Vinay, P., A. Gougoux, and G. Lemieux. 1981. Isolation of a pure suspension of rat proximal tubules. Am. J. Physiol. 241:F403-F411.

18. Harris, R. C., and T. O. Daniel. 1989. Epidermal growth factor binding, stimulation of phosphorylation, and inhibition of gluconeogenesis in rat proximal tubule. J. Cell. Physiol. 139:383-391.

19. Chamberlin, M. E., A. LeFurgey, and L. J. Mandel. 1984. Suspension of medullary thick ascending limb tubules from the rabbit kidney. Am. J. Physiol. 247 (Renal Fluid Electrolyte Physiol. 16): F955-F964.

20. Yu, L., P. E. Gengaro, M. Niederberger, T. J. Burke, and R. W. Schrier 1994. Nitric oxide: A mediator in rat tubular hypoxia/reoxygenation injury. Proc Natl. Acad. Sci. USA. 91:1691-1695.

21. Harris, R. C. 1992. Regulation of S6 kinase activity in renal proxima tubule. Am. J. Physiol. 263:F127-F134.

22. De Larco, J. E., and G. J. Todaro. 1978. Epithelioid and fibroblastic rat kidney cell clones: epidermal growth factor (EGF) receptors and the effect of mous sarcoma virus transformation. J. Cell. Physiol. 94:335-342.

23. Creely, J. J., S. J. DiMari, A. M. Howe, C. P. Hyde, and M. A. Haralson. 1990. Effects of epidermal growth factor on collagen synthesis by an epithelioid cell line derived from normal rat kidney. Am. J. Pathol. 136:1247-1257.

24. Chomczynski, P., and N. Sacchi. 1987. Single-step method of RNA isolation by acid guanidinium thiocyanate-phenol-chloroform extraction. Anal. Bio chem. 162:156-159.

25. Akai, Y., T. Homma, K. D. Burns, T. Yasuda, K. F. Badr, and R. C. Harris. 1994. Mechanical stretch/relaxation of cultured rat mesangial cells induces protooncogenes and cyclooxygenase. Am. J. Physiol. 267:C482-C490.

26. Temizer, D. H., M. Yoshizumi, M. A. Perrella, E. E. Susanni, T. Quertermous, and M-E. Lee. 1992. Induction of heparin-binding epidermal growth factorlike growth factor mRNA by phorbol ester and angiotensin II in rat aortic smooth muscle cells. J. Biol. Chem. 267:24892-24896.

27. Gaunt, S. J., J. R. Miller, D. J. Powell, and D. Duboule. 1986. Homobox gene expression in mouse embryo varies with position of the primitive streak. Nature (Lond.). 324:662-664.

28. Paller, M. S., J. R. Hoidal, and T. F. Ferris. 1984. Oxygen free radicals in ischemic acute renal failure in the rat. J. Clin. Invest. 74:1156-1164.

29. Wasil, M., B. Halliwell, M. Grootveld, C. P. Moorhouse, D. C. S. Hutchison, and $\mathrm{H}$. Baum. 1987. The specificity of thiourea, dimethylthiourea and dimethyl sulphoxide as scavengers of hydroxyl radicals. Their Protection of $\alpha 1-$ antiproteinase against inactivation by hypochlorous acid. Biochem. J. 243:867 870 .

30. Yoshizumi, M., S. Kourembanas, D. H. Temizer, R. P. Cambria, T. Quertermous, and M-E. Lee. 1992. Tumor necrosis factor increases transcription of the heparin-binding epidermal growth factor-like growth factor gene in vascular endothelial cells. J. Biol. Chem. 267:9467-9469.

31. Kume, N., and M. A. Gimbrone, Jr. 1994. Lysophosphatidylcholine transcriptionally induces growth factor gene expression in cultured human endothelial cells. J. Clin. Invest. 93:907-911.

32. Dluz, S. M., S. Higashiyama, D. Damm, J. A. Abraham, and M. Klagsbrun. 1993. Heparin-binding epidermal growth factor-like growth factor expression in cultured fetal human vascular smooth muscle cells. Induction of mRNA levels and secretion of active mitogen. J. Biol. Chem. 268:18330-18334.

33. Barnard, J. A., R. Graves-Deal, M. R. Pittelkow, R. DuBois, P. Cook, G. W. Ramsey, P. R. Bishop, L. Damstrup, and R. J. Coffey. 1994. Auto- and cross-induction within the mammalian epidermal growth factor-related peptide family. J. Biol. Chem. 269:22817-22822.

34. Marikovsky, M., K. Breuing, P. Y. Liu, E. Eriksson, S. Higashiyama, P. Farber, J. Abraham, and M. Klagsburn. 1993. Appearance of heparin-binding EGF-like growth factor in wound fluid as a response to injury. Proc. Natl. Acad. Sci. USA. 90:3889-3893.

35. Humes, H. D., and T. O. Daniel. 1990. Proto-oncogene and growth factor gene expression during the repair phase of ischemic acute renal failure. J. Am. Soc. Nephrol. 37:484 (Abstr.)

36. Igawa, T., K. Matsumoto, S. Kanda, Y. Saito, and T. Nakamura. 1993. Hepatocyte growth factor may function as a renotropic factor for regeneration in rats with acute renal injury. Am. J. Physiol. 265:F61-F69.

37. Nagaike, M., S. Hirao, H. Tajima, S. Noji, S. Taniguchi, K. Matsumoto, and T. Nakamura. 1991. Renotropic functions of hepatocyte growth factor in renal regeneration after unilateral nephrectomy. J. Biol. Chem. 266:22781-22784.

38. Zhang, G., T. Ichimura, J. A. Maier, T. Maciag, and J. L. Stevens. 1993. A role for fibroblast growth factor type-1 in nephrogenic repair. Autocrine expression in rat kidney proximal tubule epithelial cells in vitro and in the regenerating epithelium following nephrotoxic damage by $S$-(1,1,2,2-tetrafluoroethyl)-L-cysteine in vivo. J. Biol. Chem. 268:11542-11547.

39. Sakai, M., T. Homma, and R. C. Harris 1994. Production of heparinbinding epidermal growth factor-like growth factor (HB-EGF) activity increases following acute ischemic injury. J. Am. Soc. Nephrol. 5:700 (abstr.)

40. Stewart, P. M., and C. B. Whorwood. 1994. 11 $\beta$-Hydroxysteroid dehydrogenase activity and corticosteroid hormone action. Steroids. 59:90-95.

41. Whorwood, C. B., M. L. Ricketts, and P. M. Stewart. 1994. Regulation of sodium-potassium adenosine triphosphate subunit gene expression by corticosteroids and $11 \beta$-hydroxysteroid dehydrogenase activity. Endocrinology. 135:901-910.

42. Schumer, M. M C. Colombel, I. S. Sawczuk, G. Gobe, J. Connor, K. M. O'Toole, C. A. Olsson, G. J. Wise, and R. Buttyan. 1992. Morphologic, biochemical, and molecular evidence of apoptosis during the reperfusion phase after brief periods of renal ischemia. Am. J. Pathol. 140:831-838.

43. Nouwen, E. J., W. A. Verstrepen, N. Buyssens, M.-Q. Zhu, and M. E. De Broe. 1994. Hyperplasia, hypertrophy, and phenotypic alterations in the distal nephron after acute proximal tubular injury in the rat. Lab. Invest. 70:479-493.

44. Coles, H. S. R., J. F. Burne, and M. C. Raff. 1993. Large-scale norma cell death in the developing rat kidney and its reduction by epidermal growth factor. Development (Camb.). 118:777-784.

45. Shah, S. V., and P. D. Walker. 1988. Evidence suggesting a role for hydroxyl radical in glycerol-induced acute renal failure. Am. J. Physiol. 255:F438F443.

46. Toledano, M. B., and W. J. Leonard. 1991. Modulation of transcription factor NF- $\kappa \mathrm{B}$ binding activity by oxidation-reduction in vitro. Proc. Natl. Acad. Sci. USA. 88:4328-4332.

47. Schreck, R., P. Rieber, and P. A. Baeuerle. 1991. Reactive oxygen intermediates as apparently widely used messengers in the activation of the NF- $\kappa$ B transcription factor and HIV-1. EMBO (Eur. Mol. Biol. Organ.) J. 10:2247-2258.

48. Schreck, R., and P. A. Baeuerle. 1991. A role for oxygen radicals as second messengers. Trends Cell Biol. 1:39-42.

49. Yasuda, T., H-F Cheng, R. J. Coffey, Jr., and R. C. Harris. 1993. Heparin binding EGF is expressed in cultured proximal tubule cells and mesangial cells and is increased in vivo following ischemia. J. Am. Soc. Nephrol. 4:747 (Abstr.)

50. Ouellette, A. J., R. A. Malt, V. P. Sukhatme, and J. V. Bonventre. 1990 Expression of two "immediate early" genes, $E g r-1$ and c-fos, in response to renal ischemia and during compensatory renal hypertrophy in mice. J. Clin. Invest. 85:766-771.

51. Clark, A. J. L., S. Ishii, N. Richert, G. T. Merlino, and I. Pastan. 1985. Epidermal growth factor regulates the expression of its own receptor. Proc. Natl. Acad. Sci. USA. 82:8374-8378.

52. Earp, H. S., J. R. Hepler, L. A. Petch, A. Miller, A. R. Berry, J. Harris, V. W. Raymond, B. K. McCune, L. W. Lee, J. W. Grisham, and T. K. Harden 1988. Epidermal growth factor (EGF) and hormones stimulate phosphoinositide hydrolysis and increase EGF receptor protein synthesis and mRNA levels in rat liver epithelial cells: evidence for protein kinase C-dependent and -independent pathways. J. Biol. Chem. 263:13868-13874. 